\title{
Uma tela em movimento: poesia e tecnologia do arquivo
}

Estimulado pela proposta de pensar as relações entre poesia e arquivo, pergunto-me se a questão já não começa pelo próprio agenciamento dos biografemas, isto é, se a relação com o biográfico não seria, para o poeta, determinante do acervo "realidade".

A visão mais popularizada da poesia costuma entendê-la como modalidade relativamente heterodoxa da escrita autobiográfica ou, pelo menos, de uma escrita cujo sentido é biográfico. Basicamente, o poeta vive e sua escrita reflete ou contém essa experiência, transformando o poema numa espécie de repertório de fatos, memórias e sensações do sujeito. Essas experiências são os “documentos" que entulham o depósito de episódios marcantes (epifanias e traumas, efemérides e segredos) promovidos pela memória e pelo desejo à condição de acontecimentos disponíveis para a criação. A precedência do arquivo do vivido é, neste caso, claramente uma estratégia de conservação da origem.

É verdade que o estatuto de realidade desses documentos relativos ao sujeito histórico (os tais fatos biográficos) não é determinante para a poética moderna. Ocorre que o poeta se apresente como um "fingidor", que seja "trezentos e cinquenta", que ironize diante do leitor qualquer franqueza, que multiplique e disperse seus nomes, que os envolva ativamente na negociação que faz com o leitor. Pode-se dizer que, tradicionalmente, a poesia já vem problematizando o estatuto de realidade de seu material. Por outro lado, ainda que esse conteúdo não seja necessariamente "verdadeiro", cabe lembrar que a relação com ele, em muitos casos, pressupõe ou mantém um dispositivo de controle, atribuindo positividade à ideia de arquivamento. Ainda que inventados, os dados de um arquivo podem ocupar o lugar de um começo absoluto, exposto ao público graças a uma performance eficaz. E é aí que o problema se torna mais interessante.

A invenção ou a produção literária do arquivo "vida" dispensa a verificação da correspondência (integral ou parcial) do poema com o conteúdo do real. Nesse sentido, o dispositivo da ficção poética se afasta da ideia ingênua de subordinação da escrita à 
verdade do vivido. Contudo, assumida ou generalizada como ficção, parece não alterar muita coisa no modo mais comum do arquivamento, mantendo suas estratégias básicas. A não ser que a cena do poema (sua performance e seu contexto discursivo) coloque em jogo decisivamente a relação entre realidade e escrita e entre escrita e leitor, o que temos é ainda a linguagem alimentada por conteúdos supostamente estáveis e disponíveis, na perspectiva de um endereçamento igualmente definido.

Mudando a chave sem abandonar a lógica, o testemunho de uma realidade "externa" ao poeta ou à sua experiência pessoal não modifica essencialmente essa tecnologia arquivista. Muito pelo contrário, o "realismo" a ilustra ainda mais perfeitamente, quando pratica a continuidade presumida entre a escrita literária e uma narrativa de realidade. 0 interesse do caso reside no fato de que o relativo esquematismo da representação histórica torna mais imediatamente compreensíveis outras possíveis leituras da situação. O impacto das violências que atravessam o testemunho histórico (bem visível em obras que se relacionam com a experiência das guerras ou dos períodos de exceção), por exemplo, não é apenas matéria do testemunho, mas pode se tornar dispositivo que afeta sua própria integridade. Ou seja, o trabalho da memória e do luto pode ser determinante não só para a inteligibilidade do arquivo histórico, mas para seus modos de configuração. A elipse da linguagem diante do acontecimento traumático ou da morte nos leva a refletir sobre o efeito da história no discurso poético, mas igualmente sobre as estratégias empenhadas pela poesia na relação com essa narrativa histórica. Para o poeta, a violência não é exclusivamente fonte de estímulos militantes ou de sequelas traumáticas, mas de interrogações que interferem na concepção do que é a língua, do que é o testemunho, do que é o endereçamento de um texto. Bastaria a menção à obra poética e ensaística de Paul Celan para ilustrar alguns desses desdobramentos.

Nesse sentido, a história é um arquivo em permanente transformação, a ser pensado, não somente como determinante de um sujeito, revelado pela hesitação ou pelos interditos da linguagem traumatizada ou enlutada; os movimentos da narrativa histórica fazem parte do jogo da linguagem e do modo como esta entende manifestar os sentidos do arquivamento. O sujeito do poema é sujeito (do sentido) da história tanto quanto afetado por ela (isto é, potencialmente assujeitado). Em outras palavras, a linguagem de um poema tanto é um campo sintomático do sujeito quanto lugar no qual se pensa (pelo qual se dá sentido a) determinados processos de arquivamento. Na tradição crítica moderna, a palavra do poeta não é um mero subproduto de uma narrativa de realidade: ela acolhe a complexidade do real, o reinterpreta, o recoloca em jogo (inclusive, eventualmente, para se contrapor às simplificações interessadas e aos "negacionismos"). Nesse sentido, o poema não é um falatório mais ou menos leviano, mais ou menos bárbaro, que viria macular o "silêncio" imposto pelo evento histórico traumático. Há poesia "depois" (como se diz, por exemplo, "depois de Auschwitz"; "nach Auschwitz", na expressão de Adorno)? Linguagem é o que vem depois (em atraso)? Não exatamente. O que se pode objetar em relação ao atraso da representação (que viria depois do real), aplica-se também 
à participação da poesia no sentido da história. O poema não vem depois do silêncio. Por outro lado, tampouco é pura presentificação, pura inauguração de realidade. O poema é aquilo que oferece a experiência desse silêncio, o re-inaugura como coisa ao mesmo tempo passada e presente, re-criando a possibilidade de que seja "ouvido".

A problemática é muito ampla, mas vale a pena passar por ela para se resguardar de algumas confusões. As negociações entre "realidade" e "ficção", entre "fato" e "interpretação de fato", não se resolvem adequadamente pela subordinação de uma à outra, ou pela coincidência pura e simples dos opostos (sintetizada por exemplo no conhecido relativismo do "tudo é interpretação"). Para lidar com essa diferença, sem apagá-la, caberia dramatizar a instância da linguagem e o próprio gesto interpretativo, colocando-os em jogo na "produção" de realidade. Caberia, portanto, dar visibilidade aos trânsitos, às negociações, evitando apagá-los ou homogeneizá-los. Nessa operação, que encena seu poder de "resposta", o sujeito não pode ser visto como instância esvaziada, alienada daquilo que o solicita. Quando as ideias teoricamente contrastantes da "comunicação" e da "invenção" poéticas são colocadas igualmente em questão, seja no campo de sua objetividade, seja no de sua eficacidade performativa, o sujeito se torna pelo contrário hiperresponsável, isto é, comprometido também com sua linguagem, com suas pulsões, com suas estratégias de arquivamento.

Se pudermos comparar a nitidez do "fato" de realidade com a imagem icônica, bem delimitada em uma superfície visível, a linguagem de um poema teria mais a ver com a fenomenalidade espectral da projeção de um filme. Seria preciso, entretanto, ir além do sentido psicológico e defensivo da "projeção", e imaginar a superfície física de uma tela em movimento - uma tela na qual determinadas partes do tecido se dobram, em ondas, se sobrepõem a outras partes do mesmo tecido, se alternam entre aquilo que deixam ver e aquilo que escondem. No movimento que lhe é conferido, a escrita distorce as superfícies da representação, expondo relevos e reentrâncias, produzindo ênfases, insinuando cegueiras.

Uso essa metáfora da projeção pensando, é claro, no cinema que, como a literatura, tem problematizado e tornado sensível a ambivalência da relação com o documento. O trabalho contemporâneo do cinema com a "escrita" documentária é muito rico, nesse sentido, costurando ficção e realidade de inúmeras maneiras: modificando a relação entre documentarista e documentado; multiplicando as estratégias e os pontos de vista de captação e registro de imagem; transformando a pessoa "real" em ator que desempenha seu próprio papel ou em instância de uma exploração imaginária; explorando o envolvimento real do ator com a experiência de "escrita" do filme; usando ironicamente os clichês do gênero; transformando a própria vida pública em matéria de/para um documentário pessoal. Inúmeras são as estratégias, mas o essencial é entender como funcionam, isto é, quando servem para confundir os limites, divertindo ou manipulando as ingenuidades do espectador, e quando servem para sensibilizar o espectador, digamos, para erotizar esse lugar de passagem, lugar no qual se compartilha a cumplicidade entre 
o ato de ver e a produção do visível, onde aquilo que acontece não se separa da resposta ao que acontece.

A crença em um arquivo pré-definido do real, em determinado tipo de arquivamento, ao supor uma correspondência linear entre estratégias de linguagem e conteúdo de realidade (bem sintetizada pelo "Baseado em fatos reais"), parece ser o modo histórico par default da relação com a obra artística, quer seja o cinema ou a literatura. A tendência do leitor ou do espectador é ver as obras como elaborações mais ou menos eficazes, mais ou menos fiéis, mais ou menos lúdicas, de um arquivo que as precede e que permanece íntegro - independente das obras e independente de sua própria observação. A obra seria, no melhor dos casos, uma estratégia de superfície, um acréscimo de efeitos particulares que predispõem o leitor ou o espectador a determinadas ideias e a determinadas posturas. Nesse sentido, uma visão crítica da linguagem não estaria apenas na troca de um arquivo por outro (ainda que isso por vezes seja importante) ou de uma estratégia compositiva por outra, mas em uma prática artística que também seja esclarecedora quanto à sua relação com o arquivo. Deixar o destinatário de fora dessa trama é confirmar aquilo que, por sua vez, o desresponsabiliza da interpretação e mesmo de suas pulsões arquivísticas.

E aqui trago para a conversa minha experiência pessoal de escrita do livro de poemas Isto não é um documentário, publicado em 2019 (Editora 7Letras, Rio de Janeiro). Estou consciente de que o título, seguido de uma epígrafe de Ana Cristina Cesar, suscita quase de imediato a associação com o ensaio Literatura não é documento (dissertação de mestrado que a poeta defendeu na UFRJ, em 1979), obra aliás mais lembrada pelo título que pelo conteúdo. É preciso lembrar o objeto de estudo de Literatura não é documento não é bem a literatura, mas "conceitos ou representações do literário" (da literatura e do autor) presentes em filmes documentários sobre escritores brasileiros. Como se pode depreender do que eu disse até agora, o que pretendia com a negativa do meu título não era recusar a narrativa de realidade, mas reelaborar sua compreensão, seu uso, questionando a "função documentário" (para usar o termo de Ana Cristina Cesar) e colocando em primeiro plano os movimentos de fronteiras entre "vida", "escrita" e "leitor". Um livro não é um documentário, ou seja, não é um mero registro de um arquivo que o precede. Nem por isso pretende ser um elogio da mentira, da criação ou da invenção regrada. Eu poderia tê-lo chamado simplesmente Documentário e o problema de fundo continuaria o mesmo.

O poema homônimo dentro do livro dialoga, aliás, mais diretamente com Santiago, filme de João Moreira Salles. Vale a pena lembrar que Santiago é um documentário em que as imagens produzidas no passado são apresentadas e reinterpretadas à luz de uma narração presente, inclusive crítica ao ponto de vista que as gerou, interrogando as escoIhas, estratégias e exclusões que acompanhavam o projeto original. São duas linguagens que se sobrepõem e uma procura extrair da outra suas dificuldades, aquilo que ela não foi capaz de dizer, ou seja, aquilo que teria configurado seu "fracasso" como obra (filme 
não concluído) e como compreensão do que estava em jogo na relação com o mordomo, ou com a "casa" do pai. Em outras palavras, Santiago é um filme que discute de forma muito interessante o malogro de certa concepção de arquivo, de uma linguagem que não tinha sido capaz de colocar à prova as reentrâncias de sua relação com o real.

No que se refere a meu livro, abusando talvez da memória que o leitor poderia ter do paradoxo de Magritte ("Ceci n'est pas une pipe"; Isto não é um cachimbo), tratava-se de recolocar a palavra documentário em contexto ambivalente, fazendo-a oscilar entre a acumulação arquivista do conjunto de "documentos" biográficos ou históricos (informação didática, comprobatória ou publicitária do vivido) e a obra de linguagem que explicita sua paixão pelo "real”, pelo que está em jogo na "produção" desse real. Na acepção mais banal, um documentário é a obra que propõe um registro da realidade, que traz consigo um compromisso com a representação do real. Nesse sentido, de fato, meu livro não pretende ser um “documentário". Interessava-me antes problematizar esse modo de arquivamento, pensando de que maneira falar de realidade quando esta adere à linguagem de um poema.

A oscilação do modo negativo advém tanto do fato de que o livro é um livro de poemas (portanto, a princípio, sem finalidade documental) quanto (e de modo mais decisivo) do fato de que o livro não deixa de ser um documentário - se pudermos fazer os itálicos soarem como o tremor da projeção fílmica numa tela exposta aos movimentos da linguagem. Ou seja, o livro é resolutamente um documentário, quando o trabalho com os "dados" do vivido passam a ser geridos em uma tela, articulando em figuras vários discursos que dão corpo ao "real": o discurso biográfico (memorialístico, inclusive), o discurso histórico (os acontecimentos, inclusive datados), o discurso artístico (outras obras, visuais ou literárias, inclusive reescritas) etc.

Naturalmente, o "regresso" a esses discursos (públicos ou pessoais) sempre corre o risco de se tornar uma "regressão" (como observa Joana Matos Frias na orelha do livro) à "lama" melancólica, enlutada, daquilo que foi destruído. A pulsão do arquivo é também uma pulsão de morte. Analogamente, aquilo que atrai na esfera dos fatos é também aquilo que trai ("Como em Magritte ou em Godard, nestas páginas se revela assim a atração e a traição das imagens justas").

Vale lembrar que um dos textos do livro ("Essai sur le retour", escrito em francês) tematiza a pulsão do regresso (retorno, volta) à casa e explora as contínuas traições e percalços dessa ideia, focalizando o estado de viagem constitutivo do sujeito. É um texto de 1993, datado e localizado, acima do qual é inserido (na encenação gráfica de um diálogo) um texto atual (“Às voltas da casa”), igualmente datado e localizado, retomando o topos da "casa". Como em Santiago, o texto recente revisita o texto do passado. "Essai sur le retour" é um misto de várias dicções (ensaio, memórias, poesia) que eu havia preferido não publicar até então. É um texto que considerava isoladamente não concluído, "falho", quer seja pela seleção de materiais, tom e língua, quer seja pela compreensão embrionária do movimento de mão dupla do retorno (que exploro mais diretamente no 
texto de cima, "Às voltas da casa”). Revisitá-lo, em forma de diálogo textual (ao invés de simplesmente vertê-lo para o português), é um modo de fazê-lo funcionar dentro da cena ambivalente da atração e da traição do retorno (a volta à casa, ao tema, ao texto inacabado, à língua materna etc.).

Creio que esse exemplo reforça a ideia que gostaria de destacar na concepção do livro: que o problema do arquivo está visível na tecnologia do arquivo. A traição do tradutor (uma parte do livro se chama "Traduções impenitentes") em relação às imagens e textos que a escrita retoma e transforma não seria, nesse sentido, resultado de uma melancolia culposa ou, inversamente, de um gozo perverso: seria um modo de experimentar e de explicitar o movimento textual, uma certa "gestão de dados" ("data management"). A expressão, que vem ganhando importância cada vez maior no setor dito produtivo, sugere que os resultados não se restringem à produção, definindo-se e potencializando-se nos processos pelos quais são organizados e colocados à disposição. Se pensarmos essa gestão para além da mera "otimização", poderemos dizer que o real está além dos dados ou, de forma mais filosófica, que os dados não têm existência em si mesmos, antes de serem geridos.

Naturalmente, meu argumento não esgota os possíveis sentidos do arquivo, no caso em questão. E também é verdade que, em certos contextos, a discussão pode ser colocada em outros trilhos, associada menos ao texto que às suas circunstâncias, isto é, menos às tecnologias que à natureza dos dados. A discussão pode ser às vezes menos intelectual (menos "teórica", como dizem alguns) e mais interessada, do ponto de vista cultural. Estou atento a essas questões, que têm suas razões de ser em determinadas situações (a questão do "pacto" com as circunstâncias aparece no livro, assim como a atração e a traição da "simplicidade", na seção chamada "Jardim das simplicidades"), mas creio que não mudam muita coisa no que disse até agora. Eu diria mesmo, pelo contrário.

Ademais, acrescento que a escrita, para mim, nunca foi a manipulação eficiente de afetos ou de ideias, isto é, a mobilização de um arquivo determinado ou a realização positiva de um "projeto" (de diversão, de comoção ou de instrução). O que me interessa na escrita é a possibilidade de me constituir ao escrever e, desse modo, interagir com as coisas de um modo mais rico e configurar uma perspectiva sobre o mundo. Origem e destinação estão necessariamente presentes no que escrevo. E, por isso mesmo, a visão do desastre ou da inundação (colocadas no livro em diálogo com outros discursos, com o que se diz ou com o que se faz a respeito dessas circunstâncias) não é "literal", "documental", nem tampouco "traumática", no sentido daquilo que coloca o desastre em sua caixinha histórica ou em sua incomunicabilidade sintomática. São antes figuras do excesso, da destruição e da morte que recolocam à escrita o desafio permanente do debate e do afeto, da vida e da "vivacidade".

A sobreposição de lugares e de datas (assim como a montagem da capa, feita por Sofia Vaz, a partir de materiais diversos, inclusive pessoais) não pretende constituir uma prova de real, tampouco se perder no caudal da indistinção. Em um dos poemas, 
a "lama" (datada) vem diretamente de um acidente histórico (ruptura de uma barragem em Brumadinho-MG, no início de 2019) que é contemporânea, no Brasil, de um desastre político. Rompimento do pacto democrático e rompimento da barragem se aproximam. É uma figura que o tecido de um poema articula a partir de seus fragmentos, de seus materiais e falas, trazendo o desconforto à "linha de frente". A montagem, do modo como aparece no livro (fragmentos de biografia, de história, de filmes, de literatura), coloca em relevo o conflito entre a forma e o informe, em seus episódios de perda e desagregação. O real não é apenas conteúdo, mas uma cena cuja elaboração explicita a lógica do desejo, com a vida e com o outro. A figura da lama, portanto, faz parte dessa cena de excesso e de transbordamento que afeta nosso modo de lidar com os arquivos. Remete ao fato de que o arquivo não é feito apenas do que se inclui ou, ainda pior, daquilo que volta como puro sintoma (dos rejeitos de violência "desrepresada" que entornam e se esparramam como "opinião"), mas daquilo que problematiza o acúmulo e a forma, e com eles a própria ideia de controle.

Embora tenham em comum uma crítica à manipulação documentária, vale a pena lembrar a diferença retórica entre os títulos que mencionei: "Literatura não é documento" e "Isto não é um documentário". A primeira expressão soa como declaração que constata determinado modo de tratamento histórico da literatura e toma posição em relação a isso. Tem uma assertividade própria e um tom que dialoga com o tipo de debate cultural e literário que havia no Brasil, na década de 1970. No segundo caso, trata-se de uma maneira oblíqua de nomear a questão do arquivamento: por meio da negativa, um livro de poemas remete à sua relação com o contemporâneo, com os dados e com as figuras do contemporâneo. Um dos temas que mais me interessam na obra de Ana Cristina Cesar é justamente essa fricção entre o afastamento da representação documentária (em nome da criação e do "texto") e a aproximação da criação textual com o desejo, com aquilo que se deseja (o fora, a vida). Barthes é uma leitura importante para a poeta, nesse sentido. Assim como Walt Whitman, de outra maneira. "Traduzindo" o poeta americano, a propósito de A teus pés, a autora diz "isto não é um livro, isto sou eu". O texto gostaria de se transformar em pessoa; o dêitico gostaria de se ver preenchido por uma realidade diferente da do papel. Não se trata naturalmente de uma regressão romântica, mas de uma provocação poética e teórica que recoloca em primeiro plano o problema do sujeito, porém tende a se diluir em sua excessiva "verdade".

Cito um trecho do meu livro para ilustrar esse aspecto: "Aqui não tem documentário. É tudo verdade. Buquê da vida literal. Cinema de vestígios. Realismo do outro." ("Dificuldade de fundo"). A distinção "documento" / "verdade" e a reivindicação algo irônica dessa verdade ("É tudo verdade" é o nome de um festival internacional de documentários, sediado no Brasil), neste caso, apenas se sustentam se pudermos imaginar a verdade como buquê (flores, metáforas, aproximação entre coisas distantes), como vestígio (e não exatamente a coisa em si, na sua integridade), como perspectiva do outro (alteridade que afetaria sua condição de objeto, e a própria noção tradicional de "realismo"). São 
designações que aspiram a dar inteligibilidade ao caráter dilemático dessa verdade ou dessa realidade da escrita, para além de um realismo documental. Lembrando que uma das seções do livro ("Cinema”) dialoga com vários tipos de filme, inclusive na sua proximidade com o documento.

O que importa aí é o deslocamento de determinados modos de relação com o arquivo e com os hábitos de leitura que o acompanham. Se a "simplicidade" é o facilitador da partilha, a partilha não pode deixar o leitor alienado do processo, nem conceber a obra como mero espetáculo. A simplicidade que me interessa é de outra ordem. O real não é elemento de prova, tampouco mentira de um filme cuja projeção vem de trás da "plateia” ("leitor", "público") para sua contemplação iludida. Importa flagrar o arquivo em efervescência, no embate com o acontecimento, no diálogo com determinados pontos de vistas, na experiência de leitura de outros textos e de outras artes, vendo e deixando-se ver pelos "buracos" da tela.

Até por isso, não gostaria de definir o poema como "texto [que] desejaria não ser texto" (para continuar a conversa com Ana Cristina Cesar), ou seja, como algo que aspira a saltar para fora do texto. Não vejo interesse em reproduzir (ainda que em outro nível) a oposição entre texto e realidade, como se o texto fosse um dentro complexado, um lugar de ausência ou de deficiência da experiência real, um tipo de realidade diminuída. O poema é sempre uma experiência de real e, como tal, participa desse real. Mas há interesse em particularizar tal experiência, que não é apenas da ordem do desejo. Ao mesmo tempo em que participa do real, ao mesmo tempo em que deseja, o poema interpreta os processos de arquivamento que definem nossa visão da realidade, constatando que, de certo modo, tudo passa pela gestão do documento. Se o texto não é o oposto do real, pode-se dizer, por outro lado, que não há (sentido do) real sem a compreensão dos processos, sem tecnologia de arquivo. Tendo a ver o poema como aquilo que se mostra para além do imperativo do controle e de sua produção de oposições, negociando com o excesso; como linguagem que explora reentrâncias e pontos cegos, ensinando a ver em si mesma os dilemas que a constituem.

Se a epígrafe do meu livro é retirada explicitamente de Ana Cristina Cesar, é por essa experiência do dilema que comparece nela de modo mais subjacente, menos programática. A epígrafe ("Percebo ainda que sou eu que sou vivida, sou eu que sou grafada, sou eu também que escuto em surdina o velho discurso que me grafa") remete ao movimento como um todo. A poeta é grafada e percebe o discurso que a grafa. Ou seja, num certo nível de elaboração, já não há uma separação rigorosa entre quem escreve e o que é escrito. Diferente da mera declaração de fingimento, da produção de máscaras por um sujeito, a percepção é a de que minha vida está sendo escrita à medida que vivo; de que, quando escrevo, é a vida que me escreve; de que, enquanto leio, é como se já estivesse sendo escrito, sendo alimentado pelos "poetas pensados no meu seio" (como diz o poema "Enquanto leio meus seios estão a descoberto."). Há uma profunda cumplicidade entre vida e escrita, escrita e leitura. E perceber isso é também uma forma de ouvir em 
mim, subliminarmente, os atravessamentos do "velho discurso", de um outro discurso que coloca em xeque minha soberania.

O arquivo do poema não vive do controle, e tampouco da profusão e da indistinção, mas do pensamento sobre o que transborda, dos trânsitos e bloqueios entre entendimento e cegueira, entre ordem e metamorfose. Não é um documentário e tampouco me pertence. Mas só a mim cabe dizê-lo.

NOTA

* Marcos Siscar é poeta, tradutor, professor do Departamento de Teoria Literária da Unicamp e pesquisador do CNPq/Brasil. Publicou Isto não é um documentário (7Letras, 2019) e Manual de flutuação para amadores (7Letras, 2015), entre outros livros de poesia. É também autor de livros de ensaios como Jacques Derrida. Rhétorique et Philosophie (L'Harmattan, 1998), Poesia e crise (Ed. Unicamp, 2010) e De volta ao fim (7Letras, 2016), entre outros. 